\title{
Chloroquine: A Potential Drug in the COVID-19 Scenario
}

\author{
Ranjana Singh $^{1}$ (D) Viji Vijayan ${ }^{2}$
}

Received: 28 April 2020 / Revised: 21 May 2020 / Accepted: 26 May 2020 / Published online: 7 June 2020

(C) Indian National Academy of Engineering 2020

\begin{abstract}
Today, the whole world is fighting a public health emergency called 'COVID-19' caused by a new infectious virus called SARS-CoV2. Any person can catch COVID-19 from an infected person via aerosol droplets when the person coughs, sneezes, or speaks. To limit such a transmission, World Health Organization (WHO) has recommended people to wear masks and physically distance themselves by staying at least $1 \mathrm{~m}$ (3 feet) away from others. As aerosol droplets (by cough or sneeze) land on objects and surfaces around the person such as tables, doorknobs and handrails, and remain active on these surfaces for hours to days, people are advised to use soaps for at least $20 \mathrm{~s}$. and alcohol-based sanitizers as well. As the public made efforts, clinicians and researchers investigated and found that drugs which were initially used to treat other diseases may work as a treatment option for COVID-19. One of those drugs was Chloroquine and its related derivative called hydroxychloroquine. In this review article, we have systematically searched for details of COVID-19 pandemic till May 2020 and assembled few data pertaining to (i) Corona viruses; (ii) SARS-CoV2, the virus that causes COVID-19' and (iii) How chloroquine and hydroxychloroquine mediates anti-viral effect in both prophylactic and therapeutic setting. These data have been acquired mostly from PubMed and websites of WHO and Indian Council for Medical Research (ICMR). We did a systematic search and found that the properties of chloroquine are very much essential for the COVID-19 scenario. We also bring to you some evidence that the anti-lysosomal activity of chloroquine may be increased by botanicals like betulinic acid.
\end{abstract}

Keywords COVID-19 $\cdot$ SARS-CoV2 $\cdot$ Chloroquine $\cdot$ Hydroxychloroquine

\section{Introduction}

Viruses are submicroscopic infectious particles with the capacity to infect bacteria, algae, plants, animals and humans. These can be found in every ecosystem on earth. There are numerous different varieties of viruses and many are yet to be discovered. Viruses are different from other living organisms as these require a host cell to reproduce.

Ranjana Singh and Viji Vijayan have contributed equally to this work.

Ranjana Singh

bandhusg@gmail.com; ranjanasingh@uohyd.ac.in

$\triangle$ Viji Vijayan

vijivijayan@keralauniversity.ac.in

1 Department of Biotechnology and Bioinformatics, University of Hyderabad, Hyderabad, Telangana 500 046, India

2 Department of Biochemistry, University of Kerala, Kariavattom Campus, Thiruvananthapuram, Kerala 695 581, India
When virus infects a host cell (or the virus enters a living organism), the host cell gets 'enslaved' to the virus and synthesizes thousands of identical copies of the original virus. Thereafter, the host cell dies in the process of releasing newly synthesized viral particles.

A complete virus basically exists as 'virions' comprising of either DNA or RNA as genetic material encased in a protein or sometimes lipid coat. The genetic material may be single stranded or double stranded, linear or circular. The amount and arrangement of the genetic material and proteins determines the shape and sizes of the viruses. Viruses thus have complicated shapes ranging from helical to icosahedral forms. How a virus originated on earth is still a mystery and it has been thought that these were formed from DNA fragments that once escaped from a cell. With time, many viruses learned to evade host immune systems via efficient strategies producing diseases for both humans and animals. However, the last several years has witnessed a surge in many new viruses especially those from animals by a process called zoonosis. This basically occurred due to intrusion of human activity into wildlife habitats. An example of 
this is deforestation which led to changes in living habitat of bats, and infections from bats to other organisms like palm civets, pangolins, camels, horses which acted as intermediary hosts to infect humans. The increased world-wide travel is a reason that has accelerated the spread of viruses. For example, the Avian flu virus H5N1 was transported from Asia to Europe by migratory birds. The AIDS pandemic that was induced by human immunodeficiency viruses (HIV) was originally a zoonotic transmission from monkeys to humans, followed by efficient further distribution within the human population (Modrow et al. 2013). The transmission of such virus can occur by different means like vectors, respiratory droplets, feces, blisters, mucus, sexual contact, etc.

\section{Corona Virus}

Coronaviruses (CoVs) are a group of single-stranded RNA viruses belonging to a sub-family called Coronaviridae that together with Torovirinae form the Coronaviridae family of the Nidovirales order. These are the largest known RNA viruses with the potential to infect birds, humans and some other vertebrates. Although the first member of the coronavirus family was discovered in the 1930s, coronaviruses gained notoriety with the severe acute respiratory syndrome (SARS) outbreak in 2002-2003 (Belouzard et al. 2012). The International Committee on Taxonomy of Viruses (ICTV) have segregated CoVs into four genera, historically based on serological analysis and now on genetic studies: $\alpha, \beta, \gamma$, and $\delta$. These viruses are enveloped, spherical and distinct in appearance, as they possess club-shaped projections on their surface. The RNA genome of these viruses ranges from 26,000 to 32,000 bases (longest among RNA viruses). The genome is packed into a helical nucleocapsid surrounded by a host-derived lipid bilayer. RNA has a cap structure at the $5^{\prime}$ end and multiple poly (A) tail at the $3^{\prime}$ end. RNA is positive and, hence, can serve as messenger RNA (mRNA), allowing the translation of replicase/transcriptase and structural proteins. The replicase/transcriptase is composed of two overlapping open reading frames (ORFs): ORF1a and ORF1b which encode 16 non-structural proteins and 4 classical structural proteins, viz. (i) spike protein (S), (ii) envelope protein (E), (iii) membrane protein (M), and (iv) nucleocapsid protein (N) (Lodish et al. 2000). M and E proteins are involved in virus assembly. $\mathrm{S}$ protein is leading mediator of viral entry and critical player in determining host range. Modification in S protein alters cell and tissue tropism, association with other viral and host factors and changes in host pathogenicity (Belouzard et al. 2012).

CoVs mainly cause respiratory and intestinal infections with an array of clinical manifestations. So far, $7 \mathrm{CoVs}$ have been identified that produce infections in humans. These are the $\alpha$-type HCoV-229E and HCoV-NL63; the $\beta$-type HCoV-HKU1, SARS-CoV, MERS-CoV, and HCoV-OC43; and 2019-nCoV (that caused the present pandemic). HCoV229E, HCoV-OC43, HCoV-NL63, and HCoV-HKU were mildly pathogenic; while SARS-CoV or Severe Acute Respiratory Syndrome CoV, and MERS-CoV or Middle East respiratory syndrome coronavirus were highly pathogenic. The highly pathogenic CoVs infect the lower respiratory tract causing fatal acute lung injury (ALI) and acute respiratory disease syndrome (ARDS). We are yet to determine the severity of SARS-CoV2 (Abd El-Aziz and Stockand 2020).

\section{COVID-19 Disease and SARS-CoV2}

What is COVID-19? COVID-19 is a peculiar form of respiratory disorder that emerged in 2019 in a business hub called Wuhan, which is located in the Hubei Province of China. Initially, China described the disease as 'atypical' pneumonia and then declared the causative agent to be a corona virus (CoV). The Corona Study Group (CSG) of the International Committee on Taxonomy of Viruses (ICTV) after assessing the etiological agent named it SARS-CoV2 (Severe Acute Respiratory Syndrome Corona Virus2) and the disease outbreak as COVID-19 (Corona Virus DiseaseYear of Identification). The disease rapidly spread to more than 210 countries mostly via people with a travel history. As on 26th April 2020 approximately 2,80,4796 deaths were reported worldwide owing to COVID-19 (WHO 2020b). Characterization of SARS-CoV2 is under progress.

How did COVID-19 originate? The source of COVID19 outbreak is yet to be determined. Although some preliminary investigations in China identified samples in the Huanan Seafood Wholesale Market of Wuhan city to be positive for SARS-CoV2, the zoonotic source of the outbreak is still ambiguous. All throughout the pandemic, it was argued by many researchers that bats which harbor a lot of viruses (but remain unaffected by these) are a reason for the COVID-19 outbreak. This was because some bats called 'intermediate horseshoe bats' (Rhinolophus affinis) of Rhinolophidae family (widespread in central China, Southeast Asia and Indian subcontinent) carry bat corona viruses called BatCoV RaTG13 (popular in Yunnan Province) with 96\% whole genome similarity with SARS-CoV2 (Calisher et al. 2006; Zhang et al. 2020). However, direct transmission of SARS-CoV2 from these bats was not considered as evidences from recent epidemics demonstrate that efficient human-to-human transmissibility while retaining high human pathogenicity is possible only with involvement of an intermediate host. According to the current evidence, virus isolated from Malayan Pangolins (Manis javanica) celled Pangolin-CoV has $91.02 \%$ and $90.55 \%$ genetic similarity to SARS-CoV2 and BatCoV RaTG13, respectively, and hence contemplated to be one of the natural reservoirs of SARS-CoV2 (Zhang et al. 2020). 
What are the symptoms of COVID-19? For few people, COVID-19 is mild with symptoms like fever, cough, fatigue, aches and nasal congestion and in others, COVID19 is asymptomatic. The severe stage of COVID-19 occurs when the infection advances to ARDS and multiple organ failure mainly because of the inability to control the 'cytokine storm' or the wild cytokine production taking place in the body. Increased age-related problems and medical complications like diabetes, blood pressure or heart diseases are observed to worsen COVID-19 (Tisoncik et al. 2012; Abd El-Aziz and Stockand 2020; Wang and Mao 2020).

Similarities of SARS-CoV1 and SARS-CoV2: SARS CoV2 shows some similarities with SARS CoV. SARS CoV originated in the Guangdong province of China in November 2002. Palm civets were identified as intermediary hosts for SARS CoV2 which contracted the virus from bats (Falsey and Walsh 2003). SARS-CoV, however, was more `severe than COVID-19 and produced influenza-like symptoms in humans like fever, myalgia, headache, diarrhea, shivering, cough and shortness of breath. WHO described the epidemic as a serial killer that spanned from 16th November 2002 to 5th September 2003 affecting 8098 individuals in 26 different nations and causing death of 776 people (mortality rate of 9.6\%) (WHO 2003). Presently, there are reports that SARS-CoV2 virus is undergoing mutations similar to SARS-CoV virus. In both cases, mutations have occured in the spike protein. This glycoprotein is important for the association of virus with angiotensin-converting enzyme-2 receptors (ACE2) on cells of lung, intestine, liver, heart, vascular endothelium, testis, and kidney (Hamming et al. 2004). ACE2 is part of the 'Renin-Angiotensin' hormonal system of the body. Structural and biochemical studies conducted so far have shown that S protein of a SARS virus comprises of 2 functional subunits. (i) The $\mathrm{S} 1$ subunit or receptor binding domain is responsible for binding of virus to host cell receptor and (ii) $\mathrm{S} 2$ is responsible for fusion of virus with cellular membranes. Both sub-units are separated but remain noncovalently bonded in a 'pre-fusion conformation' stabilized by S1 (Andersen et al. 2020; Walls et al. 2020).

Although both SARS-CoV and SARS-CoV2 viruses have been observed to infect host cells via same ACE receptor, there have been some differences noted like an increased affinity of the virus towards the receptor in SARS CoV2. This has been presumed to be due to a mutation, i.e., N501T in spike protein of SARS-CoV2 that has somehow increased the binding affinity of virus for ACE2 (Andersen et al. 2020). Very recent reports demonstrate that the $S 1$ protein of Pangolin-CoV is similar to SARS CoV2 than RaTG13. There is evidence that 5 key amino acid residues in spike protein that are in interaction with human ACE2 are consistent between Pangolin and SARS-CoV2; while, only 4 amino acid mutations are present in RaTG13. Nonetheless, both Pangolin-CoV and RaTG12 have lost putative furin recognition at S1/S2 cleavage site that is seen in SARS CoV2 (Zhang et al. 2020). These data emerge from findings of Liu et al. (2019) who detected corona viruses in lung-infected samples of dead Malayan pangolins along with Sendai virus from the Guangdong wildlife rescue center of China which showed low identities ranging from 80.24 to $88.93 \%$ with known SARS-CoV.

What are the possible ways SARS-CoV2 infect a host cell? From the available data we have concise the information pertaining to SARS-CoV2 infection into host cell that is depicted as Fig. 1.

Step 1 Entry of virus: Viral entry is a fine interplay between the virion and the host cell and is initiated by association of the viral particle with specific proteins on the host cell surface. Thereafter, the enveloped viruses fuse their envelope with the host cell membrane to deliver their nucleocapsid to the host cell. The $\mathrm{S}$ protein plays a dual role in this viral entry process by mediating receptor binding and membrane fusion, which involves large conformational changes of the $S$ protein. During COVID19, SARS-CoV2 S-protein binds to host cell's receptor ACE2 (Belouzard et al. 2012; Andersen et al. 2020)

Step 2 The activation of the virus: Endosomal $\mathrm{pH}$ acidification is a fusion trigger for corona viruses and those like SARS-CoV rely on endosomal proteases for productive entry. As virus enters the host cell, it moves through the early and late endosomes that have low pH. In 'early' endosome, host proteases like cathepsin L facilitates cleavage of S protein in the S1-S2 boundary region leading to fusion of the viral envelope. Enzyme digestion experiments have shown that first cleavage event at the S1-S2 boundary probably enables the second cleavage event at S2' region, that is responsible for fusion activation. SARS-CoV spike protein also exhibits a certain degree of plasticity in the position of the cleavage site for priming of fusion SARS-CoV. In 'late' endosome, the viral genome with its nucleocapsid is released into the host cytoplasm (Cassell et al. 1984; Yang et al. 2004; Wang et al. 2008; Belouzard et al. 2012)

Step 3 Viral replication: Replication occurs in the cell cytoplasm and the positive-strand viral genomic RNA is transcribed into a negative RNA strand that is used as a template for the synthesis of viral mRNA (Devaux et al. 2020)

Step 4 Viral protein synthesis: ORF1a and ORF1b genes of viral genome produce two polyproteins (PPs) that are pp1a and pp1b which takeover host ribosomes 


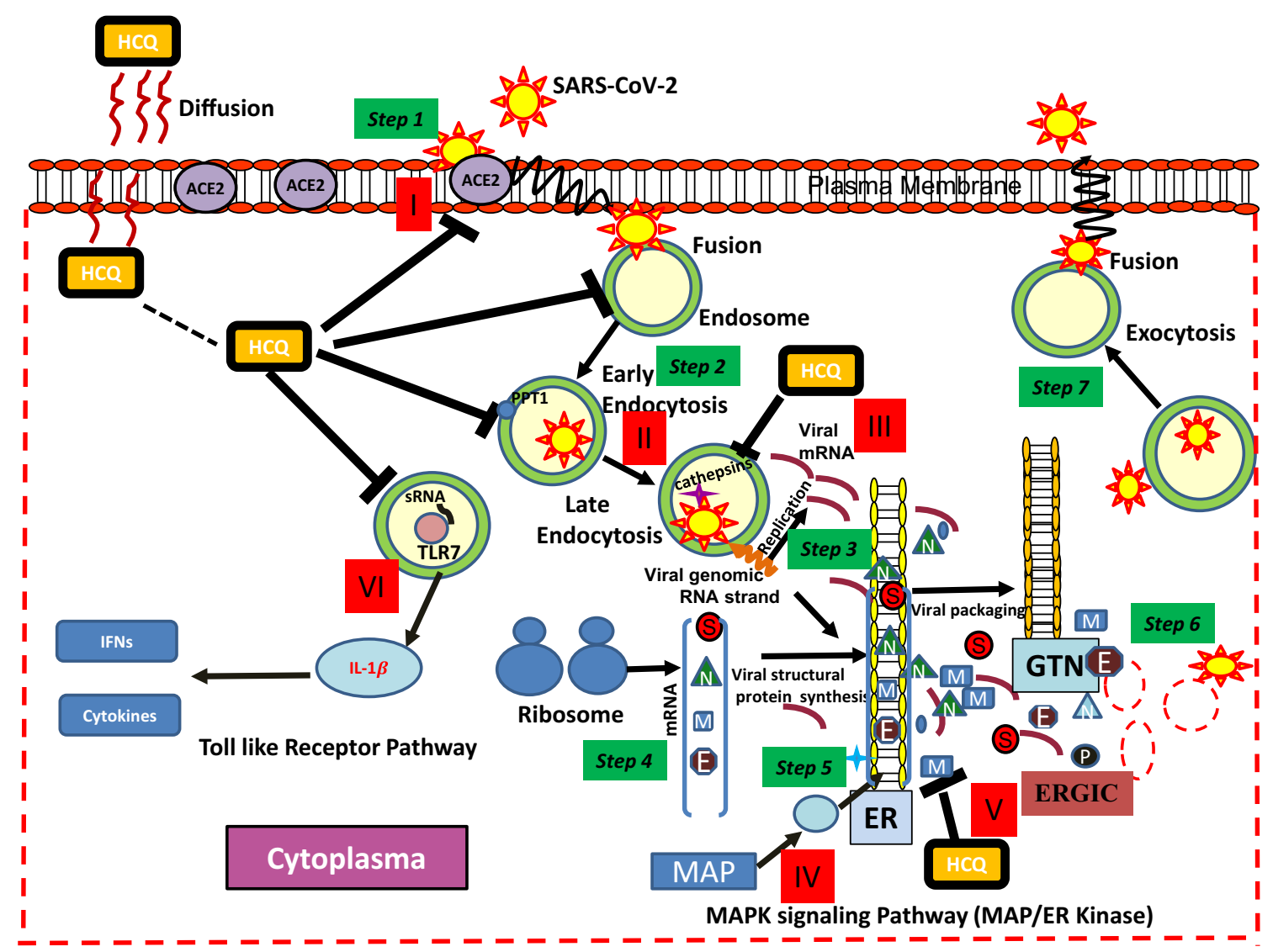

S-Spike protein, N-Nucleocapsid protein, M-Membrane protein, E-Envelop protein, ER-Endoplasmic reticulum,

GTN-Golgi trans network, ERGIC-Endoplasmic Reticulum Golgi Intermediate Compartment, TLR7- Toll Like Receptor7, Block/inhibit

Fig. 1 Schematic representation of the SARS-CoV2 replication cycle and potential targets of CQ/HCQ. Entry of the virus can be seen in the steps numbered: Step1 is entry of virus, Step2 is activation of the virus, Step3 is viral replication, Step4 is viral protein synthesis, Step5 is transport across ER and GA, Step6 is assembly of virions, Step7 is

for their own translation and replication. As ribosome machinery of the infected cells moves in favor of the virus, it synthesizes non-structural proteins (NSPs) for virus. These assemble into the replicase-transcriptase complex to support viral subgenomic mRNA synthesis. NSP1 and NSP2 have specific functions such as suppression of host gene expression (Schoeman and Fielding 2019; Devaux et al. 2020; Prajapat et al. 2020)

Step 5 Transport across ER and TGN (Trans-Golgi network): After replication, the envelope proteins such as $\mathrm{M}, \mathrm{E}$, and $\mathrm{S}$ are translated and gets transport towards the endoplasmic reticulum (ER)-Golgi intermediate compartment (ERGIC) complex to form the structure of viral envelope. Replicated genome binds to $\mathrm{N}$ protein and forms the budding and exocytosis of virions. The plausible mode of action of HCQ is via the following means I. Blocking virus entry, II. Blocking viral transport, III. Blocking fusion of endosome-viral envelope, IV. Inhibiting MAPK pathway, V. Modulating M protein and VI. Interference in TLR signaling pathway

ribonucleoprotein (RNP) complex (Prajapat et al. 2020)

Step 6 Assembly: Viral genomic RNA is then packed into the nucleocapsid and then envelope proteins are included during the budding step to form mature virions. The $\mathrm{M}$ protein, which localizes to the transGolgi network, plays an essential role during viral assembly by interacting with the other proteins of the virus mRNA (Devaux et al. 2020)

Step 7 Budding and exocytosis: Further after assembly, the virus particle comes out of the ERGIC via a budlike structure. The budding is determined by the localization of its membrane protein $\mathrm{M}$ and finally, newly formed viral particles are transported to the cell surface in vesicles and are released by exocytosis mRNA (Devaux et al. 2020) 
The mechanism of viral infection is still not complete and under study. So far, the data show that the activation of the virus occurs as it enters the host cell. During this time, a cleavage process occurs at polybasic (furin) cleavage site at $\mathrm{S} 1-\mathrm{S} 2$ boundary (formed by insertion of 12 nucleotides), which is followed by an irreversible conformational change. Through bioinformatics tool, researchers have identified the presence of a proline residue in the cleavage site and so the inserted sequence is "PRRA". Presence of proline is predicted to cause addition of O-linked glycans to S673, T678 and S686 that margin the cleavage site and produce a mucin-like domain that can shield epitope or key residues of SARS-CoV2 spike protein (Andersen et al. 2020). These observations reinforce the fact that SARS-CoV2 has been optimized for ACE, but the increased virulence in some humans is not clear. Previously it has been shown that in Avian influenza, the speedy replication and transmission of virus in high population of chicken 'selects' for attainment of polybasic cleavage sites in a protein called hemagglutinin or HA (immunodominant viral antigen of H5N1 virus). Such acquirement of polybasic cleavage sites in hemagglutinin (insertion or recombination) has been observed to convert low pathogenic viruses to very high pathogenic ones (Andersen et al. 2020). HA has a similar function with the spike protein of SARS-CoV2 but whether a similar mechanism is operating in COVID-19 needs to be validated.

We have also seen that for SARS-CoV, the evolutionary starting point (as evidenced by palm civets) was a prototype virus group with low-pathogenicity with 7 singlenucleotide variations (SNV) which caused 6 amino acid changes in the $\mathrm{S}$ protein. This group caused the early phase of the 2002-2003 epidemic. Later, further changes, i.e., 14 SNVs caused 11 amino acid residue changes that produced a "highly virulent group" which caused the middle phase of the epidemic of 2003. Thereafter, 6 SNVs caused four amino acid changes and brought about a group responsible for the late phase and the global epidemic. The neutral mutation rate of this virus during 2003 was almost constant, at around $8 \times 10^{-6} \mathrm{nt}^{-1} \mathrm{day}^{-1}$, which was the same with the most recognized RNA viruses. Afterwards, a second interspecies jump recorded in late 2003 to early 2004, caused resurgence SARS in China. This was, however, thought to be an independent interspecies transmission event, instead of residual cases of the major epidemic because the virus had lower affinity of virus for human ACE2 (Cheng et al. 2007; Kan et al. 2005; Zhang et al. 2020). Such mutations may be operational in the case of SARS-CoV2 virus as well and, hence, the differences in severity we seen in Italy, China, United Kingdom, Japan, USA and India.

What governs the affinity of a virus towards the human host cell? As for the case of SARS-CoV, it was shown that the binding specificity of virus to host cell was due to 3 prime amino acid residues in S1 protein at positions 360 ,
479, and 487. Interestingly, the patient samples in the 2003 epidemic had N479 and T487 in their S protein, while most civet samples had K/R479 and S487, which is a combination that reduces the affinity of virus for receptor. At the later stages of the epidemic (2003-2004), both the samples from humans and civet showed the presence of N479 and S487, signifying an intermediate stage of mutation of the $\mathrm{S}$ protein. Additional change to the N479 and T487 combination is believed have allowed competent human-to-human transmission. A different set of studies conducted using samples isolated from game animals (animals hunted for sports) from Guangdong also showed high nucleotide similarity with SARS-CoV. These exhibited an insertion of 29-bp between Orf $8 a$ and $O r f 8 b$ in animals, which was deleted either before or soon after crossing the species barrier to humans (Cheng et al. 2007). We are yet to figure out what are the differences in amino acid residues of SARS-CoV2 that made it effectively adhere to the ACE receptors on endothelial cells and lungs and other cells of the human body.

\section{Chloroquine and Its Role in COVID-19}

Today, governments face a very urgent need for measures to tame of the rapid spread of SARS-CoV2. Hence, clinicians and researchers across the globe are actively engaged in identifying effective therapeutic strategies to curb this deadly disease. To rush through the pandemic, one option researchers proposed was to 'repurpose' drug that has worked for similar diseases, till herd immunity is achieved (Zumla et al. 2016; Li and De Clercq 2020). When COVID19 was detected in Wuhan, China resorted to test the effectiveness of anti-viral drugs and other infectious diseases against COVID-19.

How long has it been since we know chloroquine (CQ, 9-aminoquinoline)? It is believed that a scientist named Hans Andersag and his coworkers discovered a derivative of CQ at Bayers Laboratories in 1934 (Coatney 1963). After a long line of controversy as a toxic agent, CQ reinstated its importance in 1948 by proving its effectiveness against extra-intestinal amebiasis (Conan 1948). After the World War II, WHO deployed CQ as one of its principal arms for combating malaria and now CQ is on the organization's list of essential medicines for the same. Today, CQ is known to be effective against malarial parasites of Plasmodium genus such as Plasmodium malariae, Plasmodium ovale and Plasmodium vivax but not against Plasmodium falciparum owing to the resistance developed (Mejia et al. 2013).

How does CQ help eliminate malarial parasite? During malaria, the malarial pathogen attacks red blood cell and degrades hemoglobin in vacuoles of the parasitic cell and acquires those amino acids for constructing its proteins and energy metabolism. CQ is basically a lysomotrophic agent and crosses plasma membrane and organelle membranes by 
simple diffusion process. Once inside the acidic organelles, CQ gets protonated and cannot leave the site by diffusion. $\mathrm{CQ}$, therefore, gets concentrated in the acidic organelles herein the parasitic vacuoles, changing the $\mathrm{pH}$ and facilitating the formation of a complex of 'heme and chloroquine' that prevents parasites of Plasmodium genus from drawing nutrients from the red blood cell. CQ can be transported out of cells via a protein called multi-drug resistance protein or MRP-1, an ATP binding protein (Mejia et al. 2013; Mauthe et al. 2018).

Does CQ have anti-viral effects? Literature cites that CQ exerts effects against a battery of different viruses such as flaviviruses, retroviruses and corona viruses. CQ and HCQ have demonstrated anti-viral potency against Herpes simplex virus type 1, Zika, HIV, MERS, SARS-CoV, HCoV-OC43, Chikungunya and Hepatitis C (Picot 2020). Of the different mechanisms of anti-viral action known for CQ, the most intriguing one is its ability to inhibit viruses at the entry point of host cell which happens in the case of Borna disease virus, Minute virus of mice MVMp and the Avian leucosis virus (Savarino et al. 2003). In the case hepatitis A virus, CQ inhibits uncoating of the virus and, thus, blocking its entire replication cycle (Bishop 1998, Devaux et al. 2020). Once inside the cell, CQ works by inhibiting the replication of a virus by altering the $\mathrm{pH}$ of acidic organelles that are sites of viral DNA replication (Devaux et al. 2020). Apart from blocking viral entry and viral replication, CQ can also block the final packaging process in certain viruses. Eg, in the case of infection caused by enveloped viruses like Mayaro viruses, CQ administration causes accumulation of the base in endoplasmic and trans-golgi compartments of the cell. This affects the functioning of certain low $\mathrm{pH}$-dependent proteases and glycosyl-transferases which are required for formation of viral envelopes (Savarino et al. 2003). In Flaviviridae viruses, CQ affects normal proteolytic processing of flavivirus prM protein to $\mathrm{M}$ protein (Savarino et al. 2003). For non-infectious retrovirus particles, as shown with the Avian reticuloendotheliosis virus, CQ inhibits glycosylation of envelope glycoproteins (Savarino et al. 2003). Again in the case of HIV, CQ reduces the production of the heavily glycosylated epitope $2 \mathrm{G} 12$, which is located on the gp120 envelope glycoprotein surface which is fundamental for virus infectivity. Again, these effects are likely to be attributed to the increased $\mathrm{pH}$ in trans-golgi network, which impairs the function of glycosyl-transferases involved in the post-translational processing of the HIV glycoproteins (Savarino et al. 2003).

How effective can be CQ against SARS? In 2005, Nichol et al. reported the anti-viral effects against SARS$\mathrm{CoV}$ infection in primate Vero E6 cells (derived from the African green monkey kidney) (Vincent et al. 2005). Thereafter, it was found that hydroxyl chloroquine (HCQ, which has $40 \%$ lesser adverse effects than CQ) has a better
anti-SARS-CoV-2 activity than CQ in Vero cells (Dong et al. 2020; Liu et al. 2020; Wang and Cheng 2020). An interesting mode of action of both CQ and HCQ is their ability to inhibit binding of SARS-CoV-2 viral particles to ACE2 without affecting the cellular level of ACE2 expression. This was basically via an interference with the glycosylation on ACE2 receptor, which is required for ligand recognition. This was ensured via inhibition of an enzyme called quinone reductase- 2 which is vital for biosynthesis of sialic acids and thereby glycosylation process. ACE2 when not in the glycosylated state is less efficient to interact with the SARS-CoV-2 spike protein and is one of the best ways to inhibit viral entry (Vincent et al. 2005; Wang and Cheng 2020).

CQ and HCQ also have a track record of reducing over-production of cytokines during rheumatoid arthritis, lupus erythematosus, and sarcoidosis (Rebecca et al. 2019; Schrezenmeier and Dörner 2020). These immunomodulatory effects of CQ and HCQ need highlight since they may be useful for taming the cytokine storm in the COVID-19 scenario (Conti et al. 2020). One of the proposed modulatory effect of HCQ is its ability to inhibit the activity of the nucleic acid sensor cyclic GMP-AMP (cGAMP) synthase (cGAS) by interfering with its binding to cytosolic DNA, and by stopping TLR signaling and cGAS-stimulator of interferon genes (STING) signaling (Picot 2020). At the cellular level, CQ and HCQ have been shown to inhibit immune activation by reducing signaling by Pattern Recognition Receptors (Toll-like receptor signaling) and cytokine production. Both CQ and HCQ reduce the secretion of pro-inflammatory cytokines and, in particular, TNF- $\alpha$ in macrophages. Different mechanisms have been proposed to explain the reduction in TNF- $\alpha$ by CQ and HCQ like (i) inhibition of TNF- $\alpha$ mRNA expression, (ii) inhibition in posttranslational conversion of pro-TNF $\alpha$ to a soluble mature form, (iii) a pre-translational stage by a non-lysosomotropic mechanism and (iv) reduced surface expression of TNF- $\alpha$ receptors. Apart from TNF- $\alpha, \mathrm{CQ}$ also suppresses cytokines like IL-1, IL-6 and IFN $\gamma$ in mononuclear cells, again by modulating TLR (Totura et al. 2015; Lester and Li 2014; Conti et al. 2020).

In light of the available references, the plausible interferences by CQ or HCQ are depicted in Fig. 1.

(I) Interference of virus binding to host cell: (i) The drug (CQ or HCQ) interferes with ACE2 receptor glycosylation preventing SARS-CoV2 binding to target cells. (ii) Drug limits the biosynthesis of sialic acids required for cell surface binding of SARS-CoV-2

(II) Interference in viral transport: Drug modulates the acidification of endosomes thereby inhibiting transport and formation of the autophagosome (Yang et al. 2004) 
(III) Interference in viral envelope formation: Drug inhibits the cathepsin activity in early endosome of host by increasing endosomal $\mathrm{pH}$ which further blocks cleavage of virus envelops $\mathrm{S}$ protein leading to stop fusion of the viral envelope (Wang et al. 2008, Cassell et al. 1984)

(IV) Interference to mitogen-activated protein (MAP) kinase pathway: By modulating cellular mitogenactivated protein (MAP) kinase activation, HCQ may also inhibit virus replication (Savarino et al. 2003)

(V) Modulating M protein: HCQ may alter M protein maturation and interfere with virion assembly and budding (Prajapat et al. 2020)

(VI) Interference to TLR signaling pathway: Elevation of endosomal $\mathrm{pH}$ by CQ interferes with TLR9 and TLR7 processing, hence pathogen recognition via Toll-like receptor (TLR) and thereby viral infection (Devaux et al. 2020)

The mechanism of action as detailed above for CQ or HCQ is from literature but this warrants further investigations.

Now, the above-described abilities of CQ or HCQ to function as anti-viral and immunomodulatory agent highlight the rationale for usage of CQ or its derivate as both prophylactic and therapeutic agents in clinically admissible concentrations (Shah et al. 2020). A small randomized clinical trial conducted in China with 100 patients showed that CQ had superior effects in inhibiting exacerbation of pneumonia, improving lung-imaging findings, promoting a virus-negative conversion and shortening the disease course when compared to a control drug (Jie et al. 2020; Gao et al. 2020) Another clinical trial in Marseille, France reported by Gautret et al. (2020) demonstrated that HCQ has efficacy in increasing viral clearance. In that non-randomized trial $(n=36)$ conducted, HCQ alone and in combination with azithromycin antibiotic effectively cleared viral nasopharyngeal carriage as evidenced by the gold standard PCR (polymerase chain reaction) test (versus control). The virus clearance at day 6 post-inclusion HCQ vs. control was $70.0 \%$ versus $12.5 \%$, respectively $(p=0.001)$. A higher virus clearance effect was seen with a combinational therapy of azithromycin and CQ. This combinational therapy was effective because azithromycin is an anti-viral agent that has shown efficacy against Zika and Ebola viruses (Gautret et al. 2020). However, all clinical results did not show the same picture. In a randomized study from China, patients with mild to moderate cases of COVID-19 did not show recovery rates when treated with HCQ (Gao et al. 2020). Likewise, another study conducted in France with 11 hospitalized cases also failed to confirm anti-viral activity of HCQ when administered with an azithromycin (Yazdany and Kim 2020).
A reason for the discrepancy in effect as noted among these clinical trials could be the dosage of CQ or HCQ selected; a higher dose of CQ or HCQ may be imparting untoward implications, especially if not monitored. The current doses tested may be with respect to the antimalarial effects of CQ and HCQ when the body encounters a deadly pathogen of plasmodium genus or even with respect to the other viral infections that it was tested with. Since CQ is effective at blocking viral entry, it would have better effects as a prophylactic or for patients with mild symptoms. We also see that trials were conducted during the different stages of the pandemic; at severe stages, perhaps, a different therapeutic regimen is required. Upon further mutations with time (that is seen in the different stages of a pandemic), the adherence propensity of the virus towards host cells may change (increased) that CQ or HQ alone may not be not alone sufficient as an antiviral therapy. At the same time, a toxicity profile of CQ or HCQ in combination with azithromycin versus azithromycin and CQ or HCQ should be conducted to rule out the toxicity arising from combinational therapy (Gautret et al. 2020). Additional research to carry out research on CQ and HCQ is emphasized because unlike other drugs, apart from the ability to block viral infection, these drugs also have immunomodulatory effects which is very much useful for countering the initiation of the cytokine storm seen in COVID-19 patients (Conti et al. 2020). Although this review focuses on the beneficial effects of CQ, we do not overlook some of the precautions as evidenced from clinical studies (van den Broek et al. 2020). During the course of the prophylactic or therapeutic regimen involving CQ or HCQ, frequent monitoring of hematological parameters (RBC, WBC and platelet counts), measurement of serum electrolytes, blood glucose (owing to the hypoglycemic potential of HCQ), liver function test, kidney function test and electrocardiography are warranted at time intervals to rule out any toxicity. Combinational therapy of CQ with any other allopathic drug be it azithromycin, lopinavir/ ritonavir and remdesivir is warranted only after testing in in vitro model systems and pre-clinical trials. Clinical experience has shown that chloroquine is well absorbed in the body and distributes widely in the system. It has an apparent and terminal half-life of 1.6 days and 2 weeks, respectively (Smit et al. 2020). The drug is metabolized by cytochrome $\mathrm{P} 450$ and renal clearance is responsible for one-third of total clearance of chloroquine (Smit et al. 2020). So with lower dose, it is probable that chloroquine can be used safely for an acute virus infection. But some of the potential side effects of HCQ and CQ, such as retinopathy, vomiting, diarrhea and increased risk of arrhythmia, should be also taken into account (Conti et al. 2020) and we presume that these may be countered by a combinational therapy wherein the beneficial effect of CQ may be 


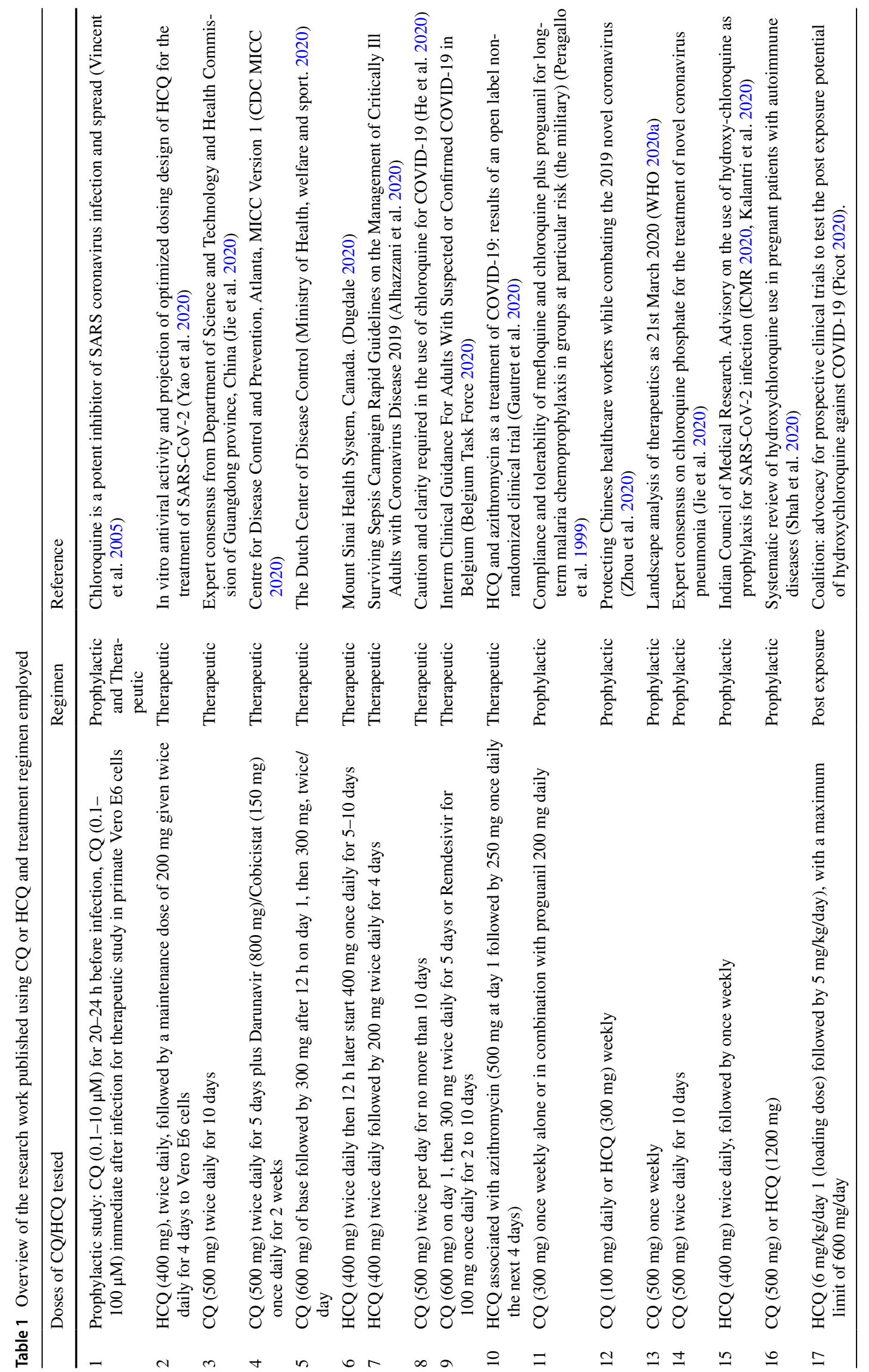


retained and the toxicity of CQ may be alleviated. Table 1 gives framework of some of the research work published using CQ or HCQ with suggested drug doses for treatment regimen of COVID 19.

While this article was under revision, we came across an extensive collaborative study by Picot (2020), which stated that in the current context of the severe worldwide health emergency, it is practical for clinicians to use HCQ even if it can only reduce viral load by $10-30 \%$. They mentioned that these are effective measures in reducing COVID-19 spread and improving clinical outcome in health care workers. They have stated that HCQ at doses matching that of the standard treatment of Systemic Lupus erythematous [which has proven safety and efficacy in terms of HCQ blood and tissue concentration adapted to bodyweight at $6 \mathrm{mg} / \mathrm{kg} / \mathrm{day}$ 1 (loading dose) followed by $5 \mathrm{mg} / \mathrm{kg} / \mathrm{day}$, with a maximum limit of $600 \mathrm{mg} /$ day in all cases] can be used as a drug for exposed people. The duration of HCQ treatment can be as long as contact with a positive patient lasts. In the case of repeated exposure to virus, then treatment is suggested to be for a min of 10 days so that there is a steady state of drug concentration in blood (Picot 2020).

\section{Anti-lysosomal Activity of CQ-Betulinic Acid Combination}

We also include in this article some details of our pilot study where we tested the effect of a combination of CQ (Sigma Aldrich, USA) and betulinic acid (Sigma Aldrich, USA) on lysosomal function in mononuclear cells, in the absence of a pathogen. BA (3ß-hydroxy-lup-20(29)-en-28-oic acid) is a triterpenoid belonging to lupane series which has a wide range of pharmacological properties like topoisomerase inhibitory potential (Chowdhuri et al. 2002), anti-cancer (Ren et al. 2010), anti-malarial (de Sa et al. 2009), antiviral (Pavlova et al. 2003) and anti-inflammatory properties (Chowdhuri et al. 2002; Vijayan et al. 2011). BA can be extracted from bark of birch tree and many other plant sources (Moghaddami and Ahmad 2012). Purified form of botanicals is a rich resource for novel antiviral drugs as these can interact with different stages of the viral life cycle, such as viral entry, replication, assembly, and release, as well as on the targeting of virus-host-specific interactions. CQ is itself a synthetic form of quinine isolated from barks of barks of cinchona trees native to Peru. So, it was of interest to check whether BA and CQ exerted an additive effect on lysosomal function. Briefly, mononuclear cells were isolated from healthy volunteers by density gradient centrifugation as detailed in Vijayan et al. (2011). Blood collected on heparinized tubes were loaded on Histopaque-1077 (Sigma Aldrich, USA) and centrifuged at $800 \mathrm{rpm}$ for $30 \mathrm{~min}$. The buffy coat layer at interface was retrieved and plated on type I collagen coated cell culture dishes containing RPMI-1640 media containing $10 \%$ FBS. After $4 \mathrm{~h}$, the media were carefully changed to remove the floating lymphocytes. The adherent mononuclear cells were cell cultured till plate reached $75-80 \%$ confluency ( $2-3$ days). Cells were then shifted to media with autologous serum and exposed to a standardized concentration of chloroquine (CQ, 2.5 micromolar) or betulinic acid (BA, $10 \mathrm{ng} / \mathrm{ml})$ and a combination of both $(\mathrm{CQ}+\mathrm{BA})$. BA was pre-treated for $20 \mathrm{~min}$ prior to $\mathrm{CQ}$ addition that was for $4 \mathrm{~h}$. $\beta$-hexosaminidase activity was determined in cell lysates by colorimetric assay as previously described by Lew and Rarrazzi (1991). Lysed cell extracts prepared by repeated freeze-thaw cycles from basal, CQ-, BA- and CQ+BA-treated cell cultures were incubated with $p$-Nitrophenyl-2-deoxy- $\beta$-D-glucosaminide $(5 \mathrm{mM})$ in $0.1-\mathrm{M}$ citrate/phosphate buffer, $\mathrm{pH} 4.5$ for $1 \mathrm{~h}$. The $p$-nitrophenol released by the enzyme-dependent hydrolysis of the substrate was quantified spectrophotometrically (Shimadzu, Japan) at 405-nm wavelength. Units of activity were defined as nanomoles of substrate per hour per mg protein. Results of the study demonstrate that a combination of BA and CQ has greater effect in reducing lysosomal activity as compared to CQ or BA (Fig. 2). This is a pilot experiment conducted in the absence of a cargo. CQ is known for inhibiting autophagy by impairing autophagosome fusion with lysosomes rather than by affecting the acidity and/or degradative activity of this organelle (Mauthe et al. 2018). So, the reason for reduction in activity of lysosome enzyme by $\mathrm{CQ}$ as seen in our pilot study requires investigation. We are assuming reduction in the count and activity of lysosomes with CQ exposure. But whether BA is potentiating the effect or not requires more sophisticated experimentations which is a futuristic aspect. We are hoping that if we can lower the dose of CQ by including BA, such combinational therapy

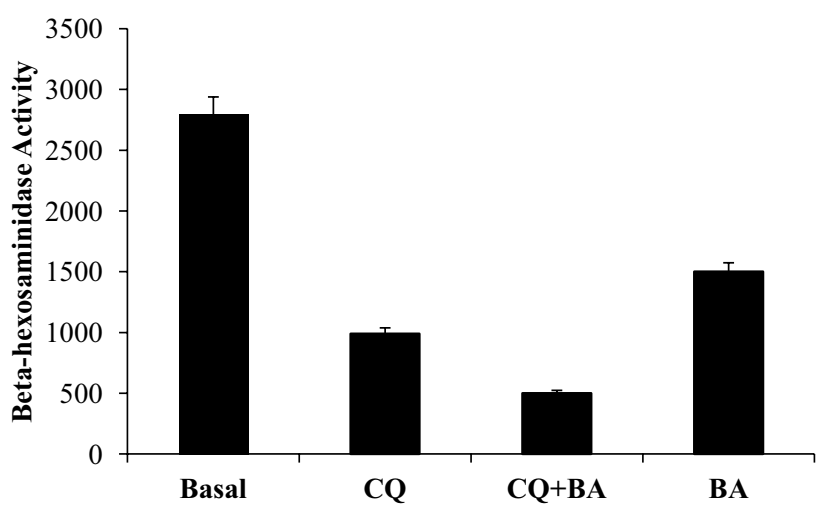

Fig. 2 The effect of a combination of betulinic acid and chloroquine on lysosomal function as evidenced by beta-hexosaminidase activity in mononuclear cells. Units of activity were defined as nanomoles of substrate per hour per mg protein. The results are a mean of 3 experiments where each experiment was conducted in duplicate. Statistical analysis was conducted by ANOVA followed by Duncan test using SPSS software 
can be considered for improving efficacy of treatment in conditions of pathogen overload.

\section{Conclusion}

CQ has been in pharmaceutical industry for 50 years now. It has low cost and is reasonably safe to use and widely available in countries where malaria is endemic, but CQ usage warrants frequent monitoring of physiological parameters to avoid any adverse effects. CQ has distinct ways of attacking a virus. CQ interferes with the glycosylation of cellular receptor of SARS-CoV to block viral infection. CQ inhibits the quinone reductase-2, which is involved in sialic acid biosynthesis required for ligand recognition. CQ changes the $\mathrm{pH}$ of lysosomes and likely inhibits cathepsins that lead to the formation of the autophagosome which cleaves SARSCoV-2 spike protein. The potency of CQ can be increased when used with an anti-viral agent. The Government of India has put up a platform for identifying the use of botanicals to treat disorders. In that context, the effect of a botanical like betulinic acid was tested. This botanical has reported that anti-viral effect may aid to reduce the dose of CQ for prophylactic or therapeutic regimen. Pre-clinical and clinical studies are required to confirm this.

\section{References}

Abd El-Aziz TM, Stockand JD (2020) Recent progress and challenges in drug development against COVID-19 coronavirus (SARSCoV-2) — an update on the status. Infect Genet Evol 83:104327

Alhazzani W, Møller MH, Arabi YM, Loeb M, Gong MN, Fan E, Oczkowski S, Levy MM, Derde L, Dzierba A, Du B, Aboodi M, Wunsch H, Cecconi MI, Koh Y, Chertow DS, Maitland K, Alshamsi F, Rhodes A (2020) Surviving sepsis campaign: guidelines on the management of critically ill adults with coronavirus disease 2019 (COVID-19). Intensive Care Med 46(5):854-887. https://doi.org/10.1007/s00134-020-06022-5

Andersen KG, Rambaut Andrew, Lipkin WI, Holmes EC, Garry RF (2020) The proximal origin of SARS-CoV-2. Nat Med 26(4):450-452

Belgium Task Force (2020) Interim clinical guidelines for patients suspected of/confirmed with COVID-19 infection, Version 7. https ://epidemio.wiv-isp.be/ID/Documents/Covid19/COVID-19_Inter imGuidelines_Treatment_ENG.pdf. Accessed 07 Apr 2020

Belouzard S, Millet JK, Licitra BN, Whittaker GR (2012) Mechanisms of coronavirus cell entry mediated by the viral spike protein. Viruses 4(6): 1011-1033

Bishop NE (1998) Examination of potential inhibitors of A virus uncoating. Intervirology 41:261-271

Calisher CH, Childs JE, Field HE, Kathry KV, Schountz T (2006) Bats: important reservoir hosts of emerging viruses. Clin Microbiol Rev 19(3):531-545

Cassell S, Edwards J, Brown DT (1984) Effects of lysosomotropic weak bases on infection of BHK-21 cells by Sindbis virus. J Virol 52(3):857-864

CDC MICC Team (2020) Treatment of confirmed COVID19 case by CDC MICC Team. https://www.medcampus.io/mnotes/proto col-for-treatment-of-confirmedcovid-19-5e5e2781e86c5d0001f7 7303. Accessed 27 Apr 2020

Cheng VCC, Lau SKP, Woo PCY, Yuen KY (2007) Severe acute respiratory syndrome coronavirus as an agent of emerging and reemerging infection. Clin Microbiol Rev 20(4):660

Chowdhuri DK, Parmar D, Kakkar P, Shukla R, Seth PK, Srimalet RC (2002) Antistress effects of bacosides of Bacopa monnieri: modulation of Hsp70 expression, superoxide dismutase and cytochrome P450 activity in rat brain. Phytother Res 16(7):639-645

Coatney GR (1963) Pitfalls in a discovery: the chronicle of chloroquine. Am J Trop Med Hyg 12:121-128

Conan NJ (1948) Chlorpquine in amebiasis. Am J Trop Med Hyg S1-28:107-110

Conti P, Ronconi G, Caraffa A, Gallenga C, Ross R, Frydas I, Kritas S (2020) Induction of pro-inflammatory cytokines (IL-1 and IL-6) and lung inflammation by coronavirus-19 (COVI-19 or SARSCoV-2): anti-inflammatory strategies. J Biol Regul Homeost Agents 34(2): 1

de Sa MS, Costa JFO, Krettli AU, Zalis MG, Maia GLA, Sette IMF, de Câmara CA, Filho JMB, Harley AMG, Santos RRD, Soares MBP (2009) Antimalarial activity of betulinic acid and derivatives in vitro against Plasmodium falciparum and in vivo in P. bergheiinfected mice. Parasitol Res 105(1):275-279

Devaux CA, Rolain JM, Colson P, Raoult D (2020) New insights on the antiviral effects of chloroquine against coronavirus: what to expect for COVID-19? Int J Antimicrob Agents 55(5):105938

Dong L, Hu S, Gao J (2020) Discovering drugs to treat coronavirus disease 2019 (COVID-19). Drug Discov Ther 14(1):58-60

Dugdale DC (April 2020) Mount Sinai health system treatment guidelines for SARS-CoV-2 infection (COVID-19). https://www.mount sinai.org/health-library/diseases-conditions/2019-novel-coron avirus-2019-ncov. Accessed 20 Mar 2020

Falsey AR, Walsh EE (2003) Novel coronavirus and severe acute respiratory syndrome. Lancet 361(9366):1312-1313

Gao J, Tian Z, Yang X (2020) Breakthrough: chloroquine phosphate has shown apparent efficacy in treatment of COVID-19 associated pneumonia in clinical studies. Biosci Trends 14(1):72-73

Gautret P, Lagier JC, Parola P, Hoang VT, Meddeb L, Mailhe M, Doudier B, Courjon J, Giordanengo V, Vieira VE, Dupont HT, Honoré S, Colson P, Chabrière E, Scola BL, Rolain JM, Brouqui P, Raoult D (2020) Hydroxychloroquine and azithromycin as a treatment of COVID-19: results of an open-label non-randomized clinical trial. Int J Antimicrob Agents. https://doi.org/10.1016/j. ijantimicag.2020.105949

Hamming I, Timens W, Bulthuis MLC, Lely AT, Navis GJ, van Gooret $\mathrm{H}$ (2004) Tissue distribution of ACE2 protein, the functional receptor for SARS coronavirus. A first step in understanding SARS pathogenesis. J Pathol 203(2):631-637

He Y, Wong K, Yang J (2020) Caution and clarity required in the use of chloroquine for COVID-19. www.thelancet.com/rheumatolo gy. Accessed 2 Apr 2020

ICMR (2020) Advisory on use of hydroxy-chloroquine as prophylaxis for SARS-CoV-2 infection. https://www.mohfw.gov.in/pdf/Advis oryontheuseofHydroxychloroquinasprophylaxisforSARSCoV2i nfection.pdf. Accessed 21 Mar 2020

Jie Z, He H, Xi H, Zhi Z (2020) Expert consensus on chloroquine phosphate for the treatment of novel coronavirus pneumonia. Zhonghua Jie He He Hu Xi Za Zhi 43(3):185-188

Kalantri S, Rathi S, Ish P, Kalantri A (2020) Hydroxychloroquine prophylaxis for COVID-19 contacts in India. https://www.thela ncet.com/action/showPdf?pii=S1473-3099\%2820\%2930313-3. Accessed 17 Apr 2020

Kan B, Wang M, Jing H, Xu H, Jiang X, Yan M, Liang W, Zheng H, Wan K, Liu Q, Cui B, Xu Y, Zhang E, Wang H, Ye J, Li G, Li M, Cui Z, Qi X, Chen K, Du L, Gao K, Zhao YT, Zou XZ, Feng YJ, Gao YF, Hai R, Yu D, Guan Y, Xu J (2005) Molecular evolution 
analysis and geographic investigation of severe acute respiratory syndrome coronavirus-like virus in palm civets at an animal market and on farms. J Virol 79(18):11892-11900

Lester SN, Li K (2014) Toll-like receptors in antiviral innate immunity. J Mol Biol 426(6):1246-1264

Lew DB, Rattazzi MC (1991) Mitogenic effect of lysosomal hydrolases on bovine tracheal myocytes in culture. J Clin Invest 88(6):1969-1975

Li G, De Clercq E (2020) Therapeutic options for the 2019 novel coronavirus (2019-nCoV). Nat Rev Drug Discov 19(3):149-150

Liu P, Chen W, Chen JP (2019) Viral metagenomics revealed sendai virus and corona virus infection of Malayan Pangolins (Malaya javanica). Viruses 11:979. https://doi.org/10.3390/v11110979

Liu J, Cao R, Xu M, Wang X, Zhang H, Hu H, Li Y, Hu Z, Zhong W, Cell Wang $M$ et al (2020) Hydroxychloroquine, a less toxic derivative of chloroquine, is effective in inhibiting SARS-CoV-2 infection in vitro. Cell Discovery 6(1):16 (Discovery volume 6, Article number: 16 (2020))

Lodish H, Berk A, Zipursky SL (2000) Molecular cell biology, 4th edn. Section 6.3, viruses: structure, function, and uses. W. H. Freeman, New York

Mauthe M, Orhon I, Rocchi C, Zhou X, Luhr M, Hijlkema KJ, Coppes RP, Engedal N, Mari M, Reggiori F (2018) Chloroquine inhibits autophagic flux by decreasing autophagosome-lysosome fusion. Autophagy 14(8):1435-1455

Meija T, Banegas EI, Mendoza M, Diaz C, Bucheli STM, Fontecha GA, Alam MT, Goldman I, Udhayakumar V, Zambrano JON (2013) Efficacy of chloroquine for the treatment of uncomplicated Plasmodium falciparum malaria in Honduras. Am J Trop Med Hyg 88(5):850-854

Ministry of Health, Welfare and Sport (2020) National Institute for Public Health and the Environment. https://lci.rivm.nl/covid-19/ bijlage/behandeladvies. Accessed 20 Mar 2020

Modrow S, Falke D, Truyen U, Schätzl H (2013) Molecular virology. Springer, Berlin, pp 1-15

Moghaddami MG, Ahmad FBH (2012) Various botanical sources of betulinic acid: a review. Asian J Chem 24:4843-4846

Pavlova NI, Savinova OV, Nikolaeva SN, Boreko EI, Flekhteret OB (2003) Antiviral activity of betulin, betulinic and betulonic acids against some enveloped and non-enveloped viruses. Fitoterapia 74(5):489-492

Peragallo MS, Sabatinelli G, Sarnicola G (1999) Compliance and tolerability of mefloquine and chloroquine plus proguanil for longterm malaria chemoprophylaxis in groups at particular risk (the military). Trans R Soc Trop Med Hyg 93(1):73-77

Picot S (2020) Coalition: advocacy for prospective clinical trials to test the post exposure potential of hydroxychloroquine against COVID-19. One Health 9:100131

Prajapat M, Sarma P, Shekhar N, Avti P, Sinha S, Kaur H, Kumar S, Bhattacharyya A, Kumar H, Bansal S, Medhi B (2020) Drug targets for corona virus: a systematic review. Indian J Pharmacol 52(1):56-65

Rebecca VW et al (2019) PPT1 promotes tumor growth and is the molecular target of chloroquine derivatives in cancer. Cancer Dis$\operatorname{cov} 9(2): 220-229$

Ren W, Qin L, Xu V, Cheng N (2010) Inhibition of betulinic acid to growth and angiogenesis of human colorectal cancer cell in nude mice. Chinese-German J Clin Oncol 9:153-157

Savarino A, Boelaert JR, Cassone A, Majori G, Caudaet R (2003) Effects of chloroquine on viral infections: an old drug against today's diseases? Lancet Infect Dis 3(11):722-727

Schoeman D, Fielding BC (2019) Coronavirus envelope protein: current knowledge. Virol J 16(1):69

Schrezenmeier E, Dörner T (2020) Mechanisms of action of hydroxychloroquine and chloroquine: implications for rheumatology. Nat Rev Rheumatol 16(3):155-166
Shah S, Shah S, Das S, Jain A, Misra DP, Negi VR (2020) A systematic review of the prophylactic role of chloroquine and hydroxychloroquine in coronavirus disease-19 (COVID-19). Int J Rheum Dis 23(5):613-619. https://doi.org/10.1111/1756-185X.13842

Smit C, Peeters MYM, van den Anker JN, Knibbe AJC (2020) Chloroquine for SARS-CoV-2: implications of its unique pharmacokinetic and safety properties. Clin Pharmacokinet. https://doi. org/10.1007/s40262-020-00891-1

Tisoncik JR, Korth MJ, Simmons CP, Farrar J, Martin TR, Katze MG (2012) Into the eye of the cytokine storm. Microbiol Mol Biol Rev 76(1):16-32

Totura AL, Whitmore A, Agnihothram S, Schäfer A, Katze MG, Heise MT, Baric RS (2015) Toll-like receptor 3 signaling via TRIF contributes to a protective innate immune response to severe acute respiratory syndrome coronavirus infection. $\mathrm{mBio}$ 6(3): $\mathrm{e} 00615-\mathrm{e} 00638$

van den Broek MPH, van den Broek JE, Möhlmann JE, Abeln BGS, Liebregts M, van Dijk VF, van de Garde EMW (2020) Chloroquine induced QTc prolongation in COVID-19 patients. Neth Heart J 29:1-4

Vijayan V, Helen A, Luxmi VR (2011) Betulinic acid inhibits endotoxin-stimulated phosphorylation cascade and pro-inflammatory prostaglandin $\mathrm{E}(2)$ production in human peripheral blood mononuclear cells. Br J Pharmacol 162(6):1291-1303

Vincent MJ, Bergeron E, Benjannet S, Erickson BR, Rollin PE, Ksiazek TG, Seidah NG, Nichol ST (2005) Chloroquine is a potent inhibitor of SARS coronavirus infection and spread. Virol J 2(1):69

Walls AC, Park YJ, Tortorici MA, Wall A, McGuire AT, David Veesler D (2020) Structure, function, and antigenicity of the SARS-CoV-2 spike glycoprotein. Cell 181(2):281-292.e286

Wang PH, Cheng Y (2020) Increasing host cellular receptor-angiotensin-converting enzyme 2 (ACE2) expression by coronavirus may facilitate 2019-nCoV infection. bioRxiv: 2020.2002.2024.963348

Wang Q, Mao J (2020) The pathogenesis and treatment of the cytokine storn in COVID-19. J Infect. https://doi.org/10.1016/j. jinf.2020.03.037

Wang H, Yang P, Liu K, Guo F, Zhang Y, Zhang G, Jiang C (2008) SARS coronavirus entry into host cells through a novel clathrin- and caveolae-independent endocytic pathway. Cell Res 18(2):290-301

WHO (2003) Update 95-SARS: chronology of a serial killer. https ://www.who.int/csr/don/2003_07_04/en/. Accessed 7 Apr 2003

WHO (2020a) Landscape analysis of therapeutics as 21st March 2020. https://www.who.int/blueprint/priority-diseases/key-action/Table of_therapeutics_Appendix_17022020.pdf. Accessed 21 Mar 2020

WHO (2020b) Coronavirus disease (COVID-19) Pandemic. Report of a WHO scientific group. https://www.who.int/emergencies/disea ses/novel-coronavirus-2019. Accessed 12 Mar 2020

Yang ZY, Huang Y, Ganesh L, Leung K, Kong WP, Schwartz O, Subbarao K, Nabel GJ (2004) pH-dependent entry of severe acute respiratory syndrome coronavirus is mediated by the spike glycoprotein and enhanced by dendritic cell transfer through DC-SIGN. J Virol 78(11):5642-5650

Yao X, Ye F, Zhang M, Cui C, Huang B, Niu P, Liu X, Li Z, Dong E, Song C, Zhan S, Lu R, Li H, Tan W, Liu D (2020) In vitro antiviral activity and projection of optimized dosing design of hydroxychloroquine for the treatment of severe acute respiratory syndrome coronavirus 2 (SARS-CoV-2). Clin Infect Dis. https:// doi.org/10.1093/cid/ciaa237

Yazdany J, Kim AHJ (2020) Use of hydroxychloroquine and chloroquine during the COVID-19 pandemic: what every clinician should know. Ann Intern Med 172(11):754-755. https://doi. org/10.7326/M20-1334

Zhang T, Qunfu WuQ, Zhang Z (2020) Probable pangolin origin of SARS-CoV-2 associated with the COVID-19 outbreak. Curr Biol 30(7):1346-1351.e1342 
Zhou P, Huang Z, Xiao Y, Huang X, Fan XG (2020) Protecting Chinese healthcare workers while combating the 2019 novel coronavirus. Infect Control Hosp Epidemiol 41:1-4

Zumla A, Chan JFW, Azhar EI, Hui DSC, Yuen KY (2016) Coronaviruses - drug discovery and therapeutic options. Nat Rev Drug Discov 15(5):327-347
Publisher's Note Springer Nature remains neutral with regard to jurisdictional claims in published maps and institutional affiliations. 